\title{
PROMOÇÃO DA SAÚDE: A CONCEPÇÃO DOS PROFISSIONAIS DE UMA UNIDADE DE SAÚDE DA FAMÍLIA
}

\author{
HEALTH PROMOTION:THE CONCEPT OF PROFESSIONALS AT A FAMILY HEALTH UNIT
}

\author{
Carol Cardoso Rodrigues ${ }^{1}$ \\ Kátia Suely Queiroz Silva Ribeiro²
}

Resumo Este artigo tem como objetivo analisar as concepções que norteiam as práticas de promoção da saúde dos profissionais de uma unidade de saúde da família em João Pessoa, Paraíba, Brasil. Realizou-se uma pesquisa qualitativa, com técnicas de entrevista e observação participante, tendo como instrumentos a entrevista semiestruturada e o diário de campo. A coleta dos dados ocorreu em abril e maio de 2010. Os informantes-chave foram seis membros da comissão gestora de uma atividade de promoção da saúde e outros dois profissionais, indicados pela comissão, totalizando oito entrevistados. As entrevistas e o diário de campo foram analisados com base no método de análise de discurso. As categorias de análise foram concepções de promoção da saúde, conhecimento da Política Nacional de Promoção da Saúde e ações de promoção da saúde do planejamento à execução. Teve como referencial teórico os documentos das conferências internacionais sobre promoção da saúde e a Política Nacional de Promoção da Saúde. Percebeu-se que os entrevistados tinham um conceito ampliado de saúde, que influencia diretamente a concepção de promoção da saúde; entretanto, há incoerência entre o discurso e a prática. Espera-se que este estudo contribua para uma reflexão das atividades de promoção da saúde desenvolvidas pelos profissionais.

Palavras-chave promoção da saúde; qualidade de vida; educação em saúde.
Abstract The purpose of this article is to analyze the concepts that guide the practices of health promotion by professionals at a family health unit in the city of João Pessoa, state of Paraíba, Brazil. A qualitative survey was carried out, with interview techniques and participatory observations, involving semi-structured interviews and field diaries. Data was collected between April and May, 2010. The key participants were six members of a health promotion management commission and another two professionals, recommended by the commission, thus totaling eight interviewees. The interviews and the field diaries were analyzed based on the discourse analysis method. The analysis categories were concepts of health promotion, knowledge of the National Health Promotion Policy and health promotion initiatives, from planning to execution. Documents from international conferences on health promotion and the National Health Promotion Policy were all used as theoretical references. The interviewees proved to have an extensive knowledge of health care, which directly influenced their concept of health promotion; however, there is incoherence between the discourse and the practice. This study is expected to contribute to a reflection on the health promotion activities undertaken by these professionals.

Keywords health promotion; quality of life; health education 


\section{Introdução}

As desigualdades e iniquidades sociais existentes no mundo, e particularmente no Brasil, colocam em destaque a discussão da promoção da saúde com um enfoque político e de planejamento. A insuficiência das ações assistenciais para dar conta dos problemas que a maior parte da população enfrenta diariamente reforça a necessidade da promoção da saúde como política e prática na responsabilização e no cuidado em saúde. Neste sentido, a saúde pode ser entendida da seguinte forma:

(...) produto de um amplo espectro de fatores relacionados com a qualidade de vida, incluindo um padrão adequado de alimentação e nutrição, e de habitação e saneamento; boas condições de trabalho; oportunidades de educação ao longo de toda a vida; ambiente físico limpo; apoio social para famílias e indivíduos; estilo de vida responsável; e um espectro adequado de cuidados de saúde (Buss, 2000, p. 166).

O significado do termo promoção da saúde mudou ao longo das últimas décadas. Partindo de uma concepção que enfatizava ações voltadas às mudanças de hábitos e comportamentos, pautadas nos aspectos biológicos do processo saúde-doença, concebe-se, atualmente, a compreensão de promoção da saúde como uma maneira de interpretar as necessidades cotidianas de saúde da população numa perspectiva coletiva e que compreende a saúde como produção social, destacando a importância dos determinantes socioeconômicos. Essa perspectiva reafirma o compromisso político quanto à necessidade de atuar sobre os fatores biológicos, sociais, econômicos e ambientais, a fim de fomentar transformações sociais (Sícoli e Nascimento, 2003).

Marco inicial de uma concepção mais progressista de promoção da saúde, o Informe Lalonde (Lalonde, 1974) identifica como principais causas de adoecimento aspectos biológicos e ambientais, além do estilo de vida. Esse documento estabelece um pensamento estratégico com o objetivo de informar, influenciar e assistir a indivíduos e organizações para que assumam maior responsabilidade em relação à saúde. Todavia, apesar dessa evolução na concepção de saúde, o informe enfoca a mudança do estilo de vida, uma perspectiva comportamental que "culpabiliza as vítimas" (Heidmann et al., 2006; Brasil, 2002).

Em 1986, ocorreu no Canadá a I Conferência Internacional sobre Promoção da Saúde, cujo produto foi o documento denominado Carta de Ottawa, que, ainda na atualidade, é uma das principais referências no debate sobre promoção da saúde. A Carta de Ottawa tem como base um conceito amplo de saúde, definindo promoção da saúde como um processo de capacitação dos indivíduos e da comunidade para melhorar sua qualidade de vida, controlando esse processo e sabendo identificar aspirações, satisfazer necessi- 
dades e modificar o meio ambiente de maneira que ele lhes possa ser favorável. Afirma que saúde é um recurso para o desenvolvimento da vida e as suas condições fundamentais são paz, habitação, educação, alimentação, renda, ecossistema estável, recursos sustentáveis, justiça social e equidade (Brasil, 2002).

Essa concepção de promoção da saúde está estreitamente relacionada com a ideia de empoderamento, entendido como um processo de capacitação dos indivíduos e comunidades para assumirem maior controle sobre os fatores pessoais, socioeconômicos e ambientais que afetam a saúde. Essa concepção de promoção da saúde também guarda relação com a participação social, compreendida como o envolvimento de membros da comunidade e organizações, dos profissionais da saúde e de gestores, entre outros, no processo de tomada de decisões (Brasil, 2006).

No âmbito brasileiro, o documento que institui a Política Nacional de Promoção da Saúde (PNPS) é referência para a discussão e o planejamento dessas ações. Esse documento apresenta a compreensão de que o processo saúde-adoecimento é determinado pela existência e condições de trabalho, qualidade de moradia, de alimentação e do meio ambiente, possibilidades de lazer, graus de autonomia e exercício da cidadania, dentre outras construções sócio-históricas. Propõe uma política transversal, integrada e intersetorial que faça dialogar os diversos setores do governo, os setores privados e a sociedade, compondo redes de compromisso e corresponsabilidade quanto à qualidade de vida da população, nas quais todos sejam participantes no cuidado com a saúde. Esse processo de construção e de implantação provoca mudanças no modo de organizar, planejar, realizar, analisar e avaliar o trabalho em saúde. Aponta as seguintes diretrizes: integralidade, equidade, responsabilidade sanitária, mobilização e participação social, intersetorialidade, informação, educação e comunicação, e sustentabilidade (Brasil, 2006).

O Sistema Único de Saúde (SUS), numa perspectiva ampliada de saúde, define que os sujeitos e coletividades elegem determinadas opções de vida como desejáveis, organizam suas escolhas e criam novas possibilidades para satisfazer suas necessidades, desejos e interesses. A estratégia de promoção da saúde apresenta-se como uma possibilidade de potencializar formas mais amplas de intervir em saúde, enfocando os aspectos que determinam o processo saúde-doença, destacando-se, dentre eles, a violência, o desemprego, subemprego, a falta de saneamento básico, a habitação inadequada e/ou ausente, a dificuldade de acesso à educação, a fome, a urbanização desordenada e a qualidade do ar e da água ameaçada e deteriorada (Brasil, 2006).

Ressalta-se a importância dessa prática para a construção teórica da saúde coletiva, por valorizar a universalidade e a integralidade, priorizar a abordagem coletiva e objetivar a redução das desigualdades sociais, o empoderamento 
e a autonomia dos sujeitos, a participação social e o saber multiprofissional. Segundo Sícoli e Nascimento (2003), a promoção da saúde busca desenvolver políticas públicas e ações que extrapolem o enfoque de risco, situando-se no campo da prevenção. Westphal (2008) aprofunda o debate, ao afirmar que os campos de ação da promoção da saúde diferem das estratégias de saúde tradicionalmente desenvolvidas pelos profissionais de saúde, e conclui que são necessárias inovações e transformações para que elas possam acontecer.

Observa-se que no nível da atenção primária à saúde, particularmente na Estratégia Saúde da Família (ESF), foco do presente estudo, as ações realizadas no âmbito da promoção da saúde geralmente estão voltadas para grupos de usuários relacionados às ações programáticas, como hipertensos, diabéticos, idosos e gestantes.

A partir da vivência no Programa de Educação pelo Trabalho para a Saúde (PET-Saúde), ${ }^{3}$ observamos ações de promoção da saúde, sob a forma de grupos de educação em saúde, analisando como são desenvolvidos, como se dá a participação dos profissionais das equipes de saúde da família, qual a importância dessas atividades para os usuários e quais as dificuldades encontradas (inexistência de materiais, dificuldade em dar continuidade ao grupo, falta de motivação dos usuários para participarem).

Com base no exposto anteriormente, salienta-se que a possibilidade de problematizar o conceito de promoção da saúde que norteia as ações das equipes de saúde da família pode contribuir para uma reflexão e reorientação dessas práticas (geralmente restritas às questões do adoecimento), direcionando-as para processos de consolidação da autonomia e ampliação do empoderamento dos sujeitos envolvidos e, com isso, promovendo mudanças mais efetivas na vida dos sujeitos. Assim sendo, propõe-se, neste trabalho, analisar as concepções que norteiam as práticas de promoção da saúde dos profissionais de uma unidade de saúde da família em João Pessoa, Paraíba.

\section{Metodologia}

Realizou-se um estudo exploratório de natureza qualitativa. De acordo com Minayo (2008), as abordagens qualitativas se conformam melhor a investigações de grupos e segmentos delimitados e focalizados, de histórias sociais, de relações.

O projeto desta pesquisa foi submetido ao Comitê de Ética em Pesquisa do Hospital Universitário Lauro Wanderley (HULW), da Universidade Federal da Paraíba (UFPB), tendo sido aprovado.

A produção dos dados ocorreu entre abril e maio de 2010, na Unidade Integrada de Saúde da Família Nova Esperança, bairro Mangabeira IV, João 
Pessoa, Paraíba. Essa unidade de saúde da família (USF) foi escolhida porque uma das autoras deste trabalho participou do PET-Saúde nessa unidade, durante o período de abril de 2009 a março de 2010, tendo se familiarizado com os profissionais e seus processos de trabalho. A unidade é composta por quatro equipes de saúde da família, totalizando 60 trabalhadores e quatro residentes multiprofissionais em Saúde da Família e Comunidade.

A atividade escolhida para ser objeto do estudo foi o grupo de idosos, por causa da sua continuidade e do fato de ser desenvolvido em conjunto pelas quatro equipes. A coordenação do grupo, que tem como função planejar as atividades do mesmo, está a cargo de uma comissão gestora, formada por representantes das quatro equipes, com um total de 13 componentes.

As técnicas de pesquisa utilizadas foram a entrevista e a observação participante. Para Richardson (1999), o observador participante tem mais condições de compreender os hábitos, atitudes, interesses, relações pessoais e características da vida cotidiana da comunidade. Existem aspectos do comportamento humano que não poderiam ser estudados satisfatoriamente de outra forma, visto que algumas pessoas apresentam dificuldades em expressar seus sentimentos por meio de palavras.

Para as entrevistas, os informantes-chave foram seis membros da comissão gestora, todos agentes comunitários de saúde (ACSs), e outros dois profissionais - um auxiliar de consultório dentário (ACD) e um dentista que, embora não fizessem parte da comissão, participavam do grupo e, por contribuírem frequentemente com ele, foram indicados pela comissão para serem entrevistados. A escolha dos membros da comissão gestora a serem entrevistados deu-se com base nas sugestões da própria comissão e também pela observação quanto à participação efetiva dos membros nas reuniões e nas atividades do grupo. Decidiu-se não entrevistar os residentes, pois estavam vinculados à equipe há apenas oito meses e possuíam laços diferentes com a comunidade e a equipe de saúde da família. As entrevistas foram realizadas na sala de reuniões da USF. O tempo de profissão dos entrevistados variou entre cinco e 22 anos.

Em relação à quantidade de entrevistas, o critério utilizado foi o ponto de saturação das informações, por se entender que é necessário ao pesquisador compreender a lógica interna do grupo em estudo, ao mesmo tempo em que alcança um entendimento das homogeneidades, da diversidade e da intensidade das informações (Minayo, 2008).

Os instrumentos escolhidos para a produção de dados foram a entrevista semiestruturada e o diário de campo, instrumento que permite ao pesquisador registrar informações que não são oriundas das entrevistas formais, como observações sobre conversas informais, comportamentos e gestos (Minayo, 2008). Neste estudo, o diário de campo foi utilizado como instrumento durante a observação nos seis encontros do grupo de idosos e 
em duas reuniões de planejamento e três reuniões da comissão gestora, ocorridas no período de dois meses.

As entrevistas foram gravadas num aparelho de MP3 e transcritas na íntegra. Como garantia de anonimato, os nomes dos entrevistados foram substituídos por números, para que suas identidades fossem preservadas, conforme compromisso ético estabelecido. A profissão dos trabalhadores foi mantida para uma melhor contextualização das falas.

A análise dos dados das entrevistas e do diário de campo foi realizada com base no método de análise de discurso, tendo sido possível estabelecer analogia entre os dados revelados nos discursos e as observações registradas. Para Pêcheux (1988, apud Minayo, 2008), o sentido de uma expressão não existe em si mesmo; ela expressa posições ideológicas no processo sóciohistórico no qual as formas de relação são produzidas.

Os dados foram organizados em grades de interpretação, após terem sido classificados em categorias, algumas definidas a priori, com base nos objetivos do trabalho e no referencial teórico (categorias analíticas), e outras que emergiram dos fatos que mais se destacaram (categorias empíricas). Os dados decorrentes da observação participante, registrados no diário de campo, também foram categorizados e analisados, em paralelo aos dados das entrevistas.

As categorias analíticas utilizadas foram conceito de promoção da saúde e ações de promoção de saúde. As categorias empíricas ficaram assim definidas: concepção de promoção da saúde, conhecimento da Política Nacional de Promoção da Saúde e ações de promoção da saúde.

Utilizaram-se como referencial teórico os documentos produzidos nas conferências internacionais sobre promoção da saúde, como a Carta de Ottawa, e também a Política Nacional de Promoção da Saúde, publicada em 2006 pelo Ministério da Saúde, que incorpora os conceitos dessas conferências.

Os informantes-chave foram previamente esclarecidos quanto ao objetivo da pesquisa. Após a autorização para a gravação de entrevista, assinaram o termo de consentimento livre e esclarecido, sendo considerados os aspectos éticos referentes à pesquisa em seres humanos preconizados na resolução n. 196/1996, do Conselho Nacional de Saúde do Ministério da Saúde.

\section{Resultados e discussão}

\section{Concepções de promoção da saúde}

Constata-se, no discurso dos entrevistados, que a concepção de promoção da saúde está intrinsecamente relacionada ao conceito de saúde. Ao serem questionados sobre promoção da saúde, os entrevistados primeiramente 
fizeram referência ao conceito de saúde; em seguida, procederam à caracterização da promoção da saúde, referindo-se à operacionalização desse conceito por meio de informação e atividades educativas.

(...) bem-estar, não só do corpo, mas da cabeça, do espírito (Dentista).

(...) não é só estar na consulta com o médico, não é somente tomar um remédio, é ter uma vida mais saudável, praticando exercícios, tendo uma boa alimentação, tendo direito ao lazer, à educação e também ao trabalho (ACS 3).

Verifica-se que os profissionais entrevistados têm um conceito ampliado de saúde, entendendo a saúde não apenas como sinônimo de ausência de doença, mas como um processo dinâmico, ligado à forma como as pessoas vivem, e como um direito do cidadão.

Nesse aspecto, nossos entrevistados se diferenciam dos resultados encontrados por Almeida (2008) e Horta et al. (2009a), nos quais os profissionais da equipe de saúde da família possuem um conceito restrito de saúde baseado na ausência de doenças. Nesse contexto, a concepção de promoção da saúde apresentava-se fragmentada e dizia respeito a evitar o adoecimento.

Ao analisar a evolução histórica da concepção de promoção da saúde, observa-se que ela muda na dependência do conceito de saúde, tornandose mais abrangente à medida que se amplia a compreensão acerca do processo saúde-doença da humanidade. Avança-se, assim, de uma concepção pautada nas mudanças de hábitos de vida e comportamentos para uma compreensão de que a promoção da saúde depende das condições de vida e de que, para tanto, os sujeitos precisam ter autonomia e lutar por seus direitos.

A compreensão ampliada de saúde possibilita uma aproximação com o conceito de promoção da saúde defendido pelas Cartas de Promoção da Saúde (Brasil, 2002). A fala dos entrevistados demonstra essa concepção, ao enfocarem determinantes sociais do processo saúde-doença, tais como dificuldade do acesso à educação, falta de saneamento básico, habitação inadequada, desemprego, entre outros. Constata-se uma maior referência à ideia de qualidade de vida, como ilustram estes trechos:

(...) não só a saúde, mas, meio ambiente, limpeza das ruas, alimentação, creio que engloba tudo, faz parte de um conjunto de promoção, para uma vida saudável (ACS 1).

(...) promoção da saúde é dar uma melhor qualidade de vida para os usuários (ACS 3).

É possível perceber que alguns profissionais entendem a promoção da saúde como uma forma de abordar e orientar os usuários quanto ao conceito 
ampliado de saúde, transmitindo informações e mostrando que a atenção à saúde ia além da assistência. Contudo, verifica-se que o discurso não avança em direção às questões mais complexas e profundas da promoção da saúde, como as da participação social e do empoderamento.

(...) promover saúde é fazer que a população tenha cidadania, direito ao lazer; promover a saúde é fazer que o cidadão entenda que saúde é um conjunto de coisas, não é não ter doenças, mas ter acesso e ter uma vida digna (ACS 2).

(...) é esclarecer tudo que for relacionado à saúde a população (ACS 1).

A despeito da compreensão conceitual ampliada, verifica-se uma tendência à atitude de tutela em relação aos usuários que não favorece os processos de autonomia desses sujeitos. O empoderamento e a participação social são princípios-chave da promoção da saúde e não devem ser separados, pois, ao se garantir o acesso à informação e se ampliar o conhecimento em saúde sem que se aumente a capacidade de controle e as perspectivas de mudança, pode-se gerar ansiedade e fomentar a sensação de impotência (Brasil, 2006).

Observa-se, também, na fala dos entrevistados uma grande associação entre promoção da saúde e educação em saúde. Segundo Alves (2004), a educação em saúde é um recurso por meio do qual o conhecimento científico pode atingir a vida cotidiana das pessoas, uma vez que a compreensão dos condicionantes do processo saúde-doença oferece subsídios para a adoção de novos hábitos e condutas de saúde. Vale ressaltar que a educação é uma das ferramentas de promoção da saúde e que esta deve implantar novas práticas de educação em saúde (Carvalho e Gastaldo, 2008).

A Carta de Ottawa estabelece que o centro do processo de promoção da saúde está no incremento do poder, e que o desenvolvimento das comunidades deve se basear nos recursos humanos e materiais nelas existentes, visando o reforço da participação popular nos assuntos da saúde. Para tanto, faz-se necessário o desenvolvimento de habilidades pessoais, e isso requer acesso a informações e oportunidades de aprendizado para assuntos da saúde. Nesse sentido, a promoção da saúde apoia o desenvolvimento pessoal e social, por meio da divulgação de informação, da educação para a saúde e da intensificação das habilidades vitais (Brasil, 2002).

Chama atenção a perspectiva de educação em saúde que aparece no discurso dos entrevistados, baseada nos moldes de uma educação tradicional:

(...) ultimamente, as atividades nas escolas, a gente está fazendo com uma palestrinha falando sobre alimentação saudável (Dentista). 
Acho que palestras educativas, atividades voltadas para hipertensos, crianças, diabéticos, saúde da mulher, saúde dos idosos. Então, assim, tudo que é voltado pra saúde, pra mim, é promoção da saúde (ACS 5).

Então, a gente leva esse conhecimento e é muito bem recebido (...). Eles gostam de muitas informações, são leigos no assunto, eles aceitam numa boa (ACD).

Essa perspectiva evidencia a ideia de que esses profissionais buscam 'depositar' o conhecimento nos usuários, algumas vezes considerando mesmo que o usuário nada sabe. O usuário, por sua vez, desvaloriza o seu próprio saber, baseando-se na crença da validade única e absoluta do saber científico.

Freire (2005) afirma que, na visão da educação bancária, a educação é um ato de depositar, de transferir valores e conhecimentos, estimulando a ingenuidade e não a criticidade do educando. O saber é uma doação dos que se julgam sábios para os que julgam nada saber.

O estudo de Cervera, Parreira e Goulart (2011) corrobora esses achados. Nele, os profissionais apresentam uma prática de promoção da saúde pautada na reeducação, na transmissão de conhecimento e no controle de doenças, com foco na interferência no comportamento da comunidade, organizada sem valorizar as práticas e o saber popular. Afirmam que a educação em saúde deve ser utilizada pelos profissionais num sentido amplo, como um instrumento de promoção da saúde, por desempenhar um importante papel facilitador para a capacitação da comunidade. Assim, trabalhadores de saúde e usuários precisam estabelecer uma relação dialógica pautada na escuta terapêutica, no respeito e na valorização das experiências, das histórias de vida e da visão de mundo.

Durante a observação participante, também ficou evidente que a prática de promoção da saúde desses profissionais era restrita, assim como o discurso deles. As ações estavam concentradas no setor saúde, e havia dificuldade para ampliá-las, alcançando-se a perspectiva intersetorial, tão necessária ao encaminhamento dos problemas que envolvem essa prática. Um exemplo disso é a parceria que existia com outro setor da gestão municipal, a Secretaria de Desenvolvimento Social de João Pessoa (Sedes/JP), uma parceria frágil e que se estabelecia na perspectiva do fornecimento de materiais para o funcionamento do grupo, principalmente ônibus para os passeios, em detrimento de ações mais estruturais, como se constata na seguinte fala:

Eu quase não tenho contato direto com a Sedes. Tem muita reunião, mas eu não tenho conseguido ir porque é no horário de reunião da equipe (...) até hoje eu não consegui nada ainda [referindo-se aos itens que havia solicitado através de ofício]. E foi prometido lanche, prometido material para manter aquele posto, liquidificador, fogão e botijão, todo mês, bebedor, panelas (ACS 6). 
Dessa forma, a relação entre esses setores mantinha uma característica assistencial, limitando a produção de saúde. A intersetorialidade é um princípio essencial na promoção da saúde, por ter como foco ações sobre os determinantes sociais e por buscar reduzir as iniquidades sociais, sendo imprescindível, para isso, a intervenção de múltiplos setores (Sícoli e Nascimento, 2003). O processo de construção de ações intersetoriais implica a troca e a construção coletiva de saberes, linguagens e práticas entre os diversos setores envolvidos, na tentativa de equacionar determinada questão sanitária, de modo que todos sejam partícipes na proteção e no cuidado com a vida (Brasil, 2006).

Verifica-se que embora os profissionais entrevistados avancem em seu discurso na visão acerca da saúde, apontando para uma perspectiva ampliada de promoção da saúde, ainda revelam limites quanto à sua concepção, na medida em que não incorporam as noções de autonomia e empoderamento, fundamentais para o desenvolvimento dessas ações.

\section{Conhecimento da Política Nacional de Promoção da Saúde}

Investigou-se o conhecimento dos profissionais quanto à Política Nacional de Promoção da Saúde visando relacionar suas práticas com as diretrizes dessa política. Ao ser questionado sobre o conhecimento da PNPS, um entrevistado apenas (ACS 2) demonstrou conhecer um pouco a política, mencionando a intersetorialidade e a equidade:

(...) promover a saúde não é só consultas médicas, mas é você conseguir trabalhar outras coisas, atividade física, cidadania, a questão da equidade, da acessibilidade (ACS 2).

(...) há muitas outras coisas que eu acredito que dá pra fazer se a gente tiver a parceria com outras secretarias, infelizmente isso ainda não acontece (ACS 2).

O entrevistado compreende que algumas ações não podem ser desenvolvidas apenas no âmbito da saúde, sendo necessária uma parceria com outros setores. A PNPS afirma que o processo saúde-doença é determinado por diversos fatores, e as intervenções nesse processo devem ser formuladas por distintos setores a fim de produzir melhoria das condições de vida. Com a intersetorialidade, os esforços tornam-se mais efetivos e eficazes, propiciando a cada setor a ampliação de sua capacidade de analisar e transformar seu modo de operar, a partir do convívio com a perspectiva dos outros setores (Brasil, 2006).

Utilizando-se a observação participante, registraram-se impressões em relação à postura desses trabalhadores com os usuários e com outros pro- 
fissionais, combinadas com as concepções acerca do conhecimento deles sobre o seu trabalho. Percebe-se que esse trabalhador se diferencia dos seus colegas pela forma crítica como discute muitas questões relacionadas ao processo de trabalho e se posiciona nos espaços de discussão da equipe de saúde da família, conforme se observa abaixo:

Então é assim, cria-se uma política no papel e, quando se vai para a prática, infelizmente as coisas não funcionam. Parece que isso é cultural e lamentável, a gente acaba levando as coisas meio que no peito e na raça mesmo (ACS 2).

Alguns profissionais relatam não se lembrar da política, outros a confundem com programas e ações da Estratégia Saúde da Família, relacionando-a a ações programáticas, como saúde do idoso, das gestantes e das crianças. Esses fatos indicam que muitos profissionais não conhecem as políticas e os programas que norteiam as suas ações:

Eu posso até conhecer [a PNPS], mas não com esse nome. Eu conheço a Curadoria do Idoso, que faz parte da política de promoção da saúde, o Caisi [Centro de Atenção Integrada à Saúde do Idoso], que é o centro de atendimento de referência para a saúde do idoso, o Clube do Idoso, que foi justamente planejado para isso, eles terem um local para as atividades de promoção a saúde (ACS 6).

Ressalte-se que um profissional confundiu o princípio da equidade com o da integralidade:

Está falando de quais princípios, da equidade? Não, é só a atenção básica. Acompanha, desde quando um usuário precisa de um atendimento aqui no posto de saúde, na unidade de saúde, até coisas mais complexas, em hospitais (Dentista).

Segundo Melo, Santos e Trezza (2005), é necessário que os profissionais da equipe de saúde da família tenham conhecimento não apenas do que é a ESF, como também das atribuições profissionais das equipes de saúde da família, considerando que conhecer a filosofia do programa é fundamental para que se possam priorizar ações de promoção e proteção de forma integral e contínua.

Os profissionais afirmaram que a PNPS não havia sido discutida com a equipe de saúde da família. Assim, o desconhecimento da política pode ser uma causa das limitações em relação ao discurso e à prática dos entrevistados quanto às atividades de promoção da saúde. Evidencia-se, assim, a necessidade do desenvolvimento de ações que transcendam às atividades atualmente realizadas, enfatizando processos que contribuam para a autonomia e o empoderamento dos sujeitos. 
A gente sabe das coisas muito superficialmente. Quem sabe, sabe porque gosta de internet, porque está sempre antenado com o site, ou assiste jornal. Mas normalmente vem um ofício dizendo que é para você fazer, mas de onde veio o embasamento científico, por que aquilo deve ser feito daquela forma, a nada disso a gente tem acesso (ACS 2).

Observa-se nessa fala a distância entre as proposições teóricas e a concretização das mesmas. Destaca-se que foram priorizadas, para os anos de 2006 e 2007, a divulgação e a implantação da PNPS, com a discussão da proposta da PNPS nos espaços de formação e educação permanente de profissionais de saúde, bem como o estímulo à inclusão do tema nos currículos (Brasil, 2006).

Entretanto, como os profissionais não tinham conhecimento dessa política, ela ainda não havia sido totalmente implantada, apresentando como fragilidade a dificuldade no entendimento dos profissionais de saúde quanto ao paradigma de promoção da saúde que ela propõe. Por isso, é de suma importância a educação permanente, pois é mediante ela que os profissionais podem apreender os conceitos relacionados ao seu trabalho, refletindo e reorientando suas práticas.

Nessa perspectiva, Merhy (2005) indica que a educação permanente tem de ter força para gerar transformações na prática do trabalhador e no seu cotidiano de produção do cuidado em saúde, implicando capacidade de problematizar. Lopes et al. (2007) completam que a educação permanente, ao se desenvolver a partir dos problemas diários que ocorrem no lócus de atuação profissional, deve levar em consideração os conhecimentos e as experiências preexistentes da equipe.

É importante enfatizar que um dos objetivos da PNPS é promover o entendimento da concepção ampliada de saúde entre os trabalhadores, e uma das estratégias de sua implantação é a qualificação dos profissionais em ações de promoção da saúde, sendo de responsabilidade das esferas de gestão estadual e municipal pôr em prática diretrizes de capacitação e educação permanente em consonância com as realidades locorregionais e regionais (Brasil, 2006).

\section{Ações de promoção da saúde: do planejamento à execução}

Conforme exposto na metodologia, escolheu-se entrevistar a comissão gestora do grupo de idosos, objetivando compreender como se dá o planejamento das atividades de promoção da saúde realizadas em grupo.

No mês de janeiro de 2010, houve duas reuniões de planejamento do grupo de idosos. A primeira contou com grande participação dos profissionais das equipes de saúde da família, fato que pode ser explicado pela pre- 
sença do apoiador matricial da unidade, porém poucos compareceram à segunda reunião. $\mathrm{O}$ apoiador matricial é um representante do distrito sanitário responsável por contribuir na organização do processo de trabalho das equipes de saúde da família, oferecendo apoio técnico e pedagógico.

Nos últimos oito anos, a gestão de saúde de João Pessoa passou a integrar equipes de saúde da família que estavam instaladas em prédios alugados em uma mesma unidade, as quais são identificadas como unidades integradas. Estas unidades abrigam entre três a quatro equipes de saúde da família e nelas o apoiador atua como um gerente. Observou-se que, na ausência do apoiador, os profissionais têm dificuldade de dar continuidade às atividades, principalmente às reuniões. Isso revela a falta de autonomia das equipes no processo de trabalho, ficando a realização das atividades dependente da presença desse profissional. Outra explicação para esse fato é a possibilidade de alguns profissionais aproveitarem a ausência do apoiador para faltar ou realizar outras atividades do seu interesse.

Nessas reuniões, estabeleceu-se um cronograma de atividades para o grupo até o mês de junho de 2010, propondo-se as seguintes atividades: ação educativa, passeio, bingo, jogos recreativos, oficina de artesanato, visita para doações, chá dançante e ensaios de quadrilha. Nenhum usuário participou desse planejamento, tampouco foram trazidas suas ideias e sugestões para serem debatidas pelo grupo.

Na prática, observou-se que o planejamento inicialmente proposto foi quase todo modificado. Alguns fatores parecem estar relacionados com isso: a desorganização da comissão gestora; as dificuldades de comunicação entre seus membros; e, ainda, impedimentos de ordem institucional, tais como a burocracia e a falta de recursos. Deve-se considerar que o trabalho na atenção primária é bastante dinâmico e, por isso, nem sempre é possível concretizar o que foi planejado. Percebe-se que, apesar de a comissão gestora ter representantes de todas as equipes, não era feito um repasse das atividades do grupo para o restante da equipe:

No começo do ano, fizemos o planejamento do ano até a avaliação final do mês de dezembro. Só que, desse planejamento, vimos, com as quatro equipes, o que se podia e o que não se podia fazer; houve alguns atropelos, por burocracias, e não se conseguiram determinadas coisas: foram passando de uma semana para a outra e (...) fazendo outras coisas, para não ter de perder a semana seguinte (ACS 6).

Como o trabalho em equipe implica o compartilhar do planejamento, a divisão de tarefas, a cooperação e a colaboração, o diálogo é um elemento imprescindível para o desenvolvimento adequado das atividades (Araújo e Rocha, 2007). Assim, a falta de diálogo entre os profissionais envolvidos em determinada atividade compromete o seu êxito. 
Atualmente, a comissão gestora é composta de oito ACSs, um técnico de enfermagem e quatro residentes. Durante a observação participante no grupo de idosos, constatou-se que a maioria dos profissionais das equipes não havia participado da atividade, apesar de o grupo de idosos fazer parte de suas agendas. É evidente que vários fatores estão envolvidos nesse distanciamento, tais como a sobrecarga de trabalho, a necessidade de tempo livre para realizar outras atividades e a insatisfação profissional. Todavia, percebeu-se, por parte de alguns trabalhadores, desinteresse e falta de compromisso em desenvolver ações fora do âmbito do atendimento. Com isso, a comissão gestora muitas vezes levou adiante o grupo sem o apoio das equipes:

Apesar de ser um grupo integrado e que foi combinado junto com as quatro equipes, sempre aparece um profissional que está envolvido com outra atividade ou que não veio, não dá muita importância ao grupo (ACS 6).

A observação participante ocorreu em seis encontros do grupo e apenas um encontro teve participação dos outros profissionais: ACD, ACS, enfermeiro, médico e técnico de enfermagem. Essa participação ocorreu durante um passeio à praia, para o que se exigia a presença desses profissionais. Verificou-se, também, que as atividades em espaços externos à unidade têm maior receptividade pelo profissional.

Melo, Santos e Trezza (2005) afirmam que, para os profissionais, a falta de materiais educativos e didáticos, a inexistência de locais adequados para a realização das palestras, a resistência e o baixo nível de escolaridade dos usuários podem ser frustrantes, causando desmotivação para a realização de ações de educação em saúde.

No nosso estudo, os entrevistados que não faziam parte da comissão gestora foram interrogados quanto ao planejamento de outras ações de promoção da saúde. Percebe-se que, muitas vezes, quando o profissional participa das atividades em grupo, passa conhecimentos do seu núcleo de saber específico, ou seja, cada profissional contribui com assuntos da sua área:

Duas vezes por mês, ou uma vez pelo menos, a gente tem o hiperdia na igreja, sempre tem alguém que vai conversar com eles sobre qualquer tema. A gente já teve a parte de odontologia, que de vez em quando eu faço uma conversa, orientações... (Dentista).

Japiassu (1976, apud Santos e Cutolo, 2004) caracteriza a interdisciplinaridade como um trabalho partilhado por vários ramos do saber, de forma integrada e convergente, levando a uma melhor operacionalização dos princípios do SUS e tornando reais conceitos como universalidade, equidade e integralidade. Ficou evidente, no grupo observado, a dificul- 
dade em fazer essa interdisciplinaridade acontecer, e a própria multidisciplinaridade estava comprometida, pois a maioria dos encontros do grupo não contava com a presença dos diversos núcleos profissionais presentes na equipe de saúde da família.

Quanto às atividades desenvolvidas no grupo, elas estão centradas no lazer: passeios, dança ou oficinas de artesanato. Os profissionais buscam promover momentos de lazer para os idosos, por entenderem que alguns deles não têm acesso a esse tipo de atividades. Esses momentos são importantes, porém os profissionais devem estimular a autonomia dos idosos, de modo que eles mesmos possam promover atividades de lazer para si, e não se tornem dependentes da equipe:

Em particular, o idoso é uma pessoa muito carente; ele gosta muito dessas pessoas, se apega muito fácil, a gente está trazendo os idosos da nossa comunidade, tirando de dentro de casa, de ficar assistindo televisão, ocioso, sem ter o que fazer e aqui está se fazendo um pouco de tudo com eles (ACS 5).

Uma das atividades realizadas durante a observação participante foi um chá dançante, com o primeiro ensaio da quadrilha. Os idosos estavam animados e todos participaram e se divertiram, sem demonstrar cansaço. O lazer pode ser visto como uma saída, uma busca por alternativa, permitindo o desenvolvimento da sociabilização, da convivência e do compartilhamento grupal. Entretanto, para o lazer ser uma estratégia de promoção de saúde, é preciso criar ações dirigidas aos determinantes de saúde, assegurando a proteção à saúde, deve ser eficiente na redução de danos e é preciso garantir o bem-estar em todas as dimensões do ser humano (Canton, 2008). Essa dimensão estava faltando no grupo.

De acordo com Teixeira (2002), torna-se necessário que o grupo, como estratégia de promoção de saúde, configure-se como espaço de reflexão e manutenção da autonomia, no sentido da preservação das escolhas, trabalhando com competências, e não com perdas. Necessita ser, também, um espaço de construção do empoderamento. O idoso inserido em grupos que trabalham com uma perspectiva crítica da realidade é capaz de refletir sobre a velhice, criando possibilidades de estar no mundo de forma mais prazerosa.

Percebeu-se, ao longo da observação, que as atividades desenvolvidas influenciam a vida dos usuários, principalmente nos aspectos emocionais, relacionados à solidão. No entanto, os profissionais não refletem a respeito das atividades que são realizadas, e, por não dialogarem com os idosos, não os estimulam a refletir também, a discutir o que se busca com aquela atividade. Um exemplo dessa situação é o de uma oficina de artesanato para a confecção de flores de viés para o bazar da Feira de Saúde, quando não se 
mencionou a importância dessas atividades manuais para o idoso e para sua vida pessoal. A falta de problematização e de discussão das questões abordadas causa uma perda em termos de potencialidade do grupo e da possibilidade de que os temas trazidos possam repercutir no cotidiano de seus integrantes. Assim, ações educativas realizadas de forma acrítica transformam o trabalhador em um repassador de informações, impedindo-o de aprofundar a reflexão (Rosso et al., 1999, apud Cervera, Parreira e Goulart, 2008). Os trabalhadores do grupo estudado perderam oportunidades de problematizar com os usuários as experiências vivenciadas e de contribuir para reflexões críticas e potencialmente geradoras de autonomia.

O objetivo da educação dialógica não é o de informar para a saúde, mas o de transformar saberes existentes, o de ser emancipatória. Nessa perspectiva, a educação visa ao desenvolvimento da autonomia e da responsabilidade dos indivíduos no cuidado com a saúde, pela compreensão da situação de saúde, sem a imposição de um saber técnico-científico pelo profissional. A comunicação dialógica visa à construção de um saber que capacite os indivíduos a decidirem quais as escolhas mais apropriadas para promover, manter e recuperar a sua saúde (Alves, 2004).

Outro importante aspecto observado foi a dificuldade para mediar a atividade demonstrada pelos profissionais que desenvolveram o grupo, prejudicando a sua dinâmica. Em consequência disso, nem sempre os idosos entendem a atividade que foi proposta, dispersando-se ou optando por não participar. Verificou-se que nenhum profissional toma para si a função de facilitar o grupo: a responsabilidade é de todos e ao mesmo tempo de ninguém.

Melo, Santos e Trezza (2005) afirmam ser necessário que os profissionais estejam preparados pedagogicamente para exercer as atividades educativas. Acrescente-se que, no panorama do cuidar, o trabalhador que cuida necessita de habilidades técnicas, mas também de competências emocionais nas relações interpessoais (Cervera, Parreira e Goulart, 2008). Percebe-se, assim, que o trabalho de educação em saúde também impõe a necessidade de processos de educação permanente.

Por outra parte, no cotidiano da vivência em grupo, a metodologia utilizada e a condução do grupo pelo coordenador fazem diferença e trazem relevância para os participantes para que, dessa forma, o grupo não se torne um encontro de pessoas doentes, conforme alertam Horta et al. (2009b).

Constatou-se que os ACSs não se sentem capacitados para desenvolver atividades de educação em saúde. No entanto, costumam desenvolvê-las, muitas vezes sozinhos, por causa da grande demanda de atendimento clínico que recai sobre os outros profissionais da equipe. $O$ fato de não terem formação de nível superior faz os ACS se sentirem inseguros ao serem procurados pela comunidade para resolver questões de saúde que fogem ao seu domínio, conforme ilustra a fala a seguir: 
A gente vai atrás de pessoas capacitadas para fazerem essa parceria e ensinarem um pouco mais para eles (ACS 3).

De acordo com Almeida (2008), os ACSs encontram dificuldades em visualizar as fronteiras de sua atuação, não compreendem de forma integral o seu papel, assim sentem-se inseguros com o desempenho de seu conhecimento teórico. Cabe ressaltar, porém, que as demandas de saúde que surgem nos grupos implicam a necessidade de múltiplos saberes, necessidades que nem os ACSs nem qualquer outro profissional sozinho são capazes de dar conta.

Por isso, a importância das ações de educação permanente, proporcionando a esse trabalhador não apenas segurança no seu processo de trabalho, mas também a sua valorização e do seu conhecimento 'popular', acrescido do conhecimento técnico-científico. Todavia, isso não elimina a necessidade da participação nos grupos dos demais trabalhadores da equipe.

É importante ressaltar iniciativas da comissão gestora visando melhorar o trabalho com o grupo, tais como avaliar a atividade realizada após o término do encontro e pedir aos participantes sugestões para os próximos; essas iniciativas demonstram interesse pelos desejos e necessidades do grupo, possibilitando uma maior aproximação das atividades de promoção da saúde com as reais necessidades da população.

Após a reunião do grupo, a gente faz uma pequena avaliação - isso para não deixar toda equipe (...) perder o entrosamento ou se dispersar. Eu acho importante para que a gente não se afaste uns dos outros (ACS 1).

Muitas vezes a gente pergunta a eles o que eles querem fazer, porque a gente faz um trabalho para eles, e tem de dar importância à vontade deles também (ACS 3).

Quando um grupo é construído com base nas necessidades apresentadas pela comunidade seus resultados são a diminuição da demanda e a melhora da autoestima dos indivíduos (Horta et al., 2009b). Salienta-se, desse modo, a importância de ter como ponto de partida para o planejamento do grupo os interesses e as necessidades de seus participantes.

Ficaram evidentes as dificuldades de planejamento das atividades do grupo, bem como a concentração da responsabilidade em relação às mesmas nos agentes de saúde. A despeito da iniciativa de avaliar com os participantes as atividades e solicitar-lhes sugestões, o planejamento das atividades de promoção da saúde ainda está centrado na perspectiva da equipe. 


\section{Considerações finais}

A concepção de promoção da saúde presente no discurso e na prática dos entrevistados avança, ao considerar saúde de forma ampliada, mas se apresenta restrita no que tange à operacionalização das ações, pois ainda está muito centrada na mudança de comportamento dos indivíduos. Caracteriza-se pela busca de melhorias na qualidade de vida, porém não capacita o usuário a buscar essa melhoria, não estimula os processos geradores de autonomia, e o usuário depende, assim, do que é oferecido pela equipe de saúde.

A PNPS foi implantada em 2006, mas as equipes de saúde da família ainda não têm conhecimento do teor dela. Isso reflete a distância existente entre o que está definido nos documentos que regulamentam as políticas públicas e o que se efetiva no cotidiano dos trabalhadores que operam essas propostas.

Outra questão que merece destaque é a dificuldade percebida em alguns profissionais para atuarem como facilitadores das atividades de educação em saúde, evidenciando a necessidade da educação permanente, uma importante ferramenta que deve ser utilizada para atender às necessidades das equipes de saúde da família. Ressalta-se, assim, a inexistência ou a insuficiência dos processos de educação permanente, causando graves prejuízos, não apenas para a Política Nacional de Promoção da Saúde, mas também para a consolidação de todas as propostas relativas ao funcionamento e ao aprimoramento do sistema de saúde.

Quanto ao planejamento das atividades, verificou-se que os profissionais priorizaram para esse grupo de idosos as atividades de lazer. A existência da comissão gestora, que faz um planejamento semanal das atividades a serem realizadas, parece gerar uma desresponsabilização por parte dos outros profissionais para com o grupo. Enfatiza-se, então, que as ações de promoção da saúde devem ser planejadas a partir dos seus princípios e de acordo com a realidade local, a fim de proporcionar mudanças mais efetivas, fazendo com que os indivíduos sejam capazes de intervir nos determinantes de saúde. Cabe ressaltar a sobrecarga de trabalho imposta às equipes de saúde da família, em função da quantidade de famílias no território adscrito com grande demanda assistencial, um fator que dificulta o envolvimento de toda a equipe nas ações de promoção da saúde.

Este estudo apresenta limitações pelo fato de ter sido desenvolvido em apenas uma unidade integrada de saúde da família, ressaltando-se a necessidade de que seja ampliado para outros serviços. Indica-se, também, a necessidade de estudos que avaliem o desenvolvimento das atividades de promoção da saúde na perspectiva dos usuários. Espera-se, contudo, que ele contribua para uma reflexão das atividades de promoção da saúde desen- 
volvidas pelos profissionais e para uma reorientação delas, sabendo-se que esse é um processo gradual de ressignificações que pode proporcionar mudanças efetivas na vida dos usuários.

\section{Colaboradores}

Os autores trabalharam em conjunto em todas as etapas de produção do manuscrito.

\section{Notas}

1 Residente Multiprofissional em Saúde da Família da Universidade Estadual de Ciências da Saúde de Alagoas (Uncisal), Maceió, Alagoas, Brasil. Graduada em Fisioterapia pela Universidade Federal da Paraíba (UFPB). < carolcrodrigues@hotmail.com>

Correspondência: Rua Doutor Jorge de Lima, 580, Condomínio Bela Vista II, casa 103, CEP 57010-300, Trapiche da Barra, Maceió, Alagoas, Brasil.

2 Professora adjunta de Fisioterapia da Universidade Federal da Paraíba (UFPB), João Pessoa, Paraíba, Brasil. Doutora em Educação pela Universidade Federal da Paraíba (UFPB). $<$ katiaqsribeiro@yahoo.com.br>

3 O PET-SAÚDE é um programa do Ministério da Saúde cujo objetivo geral é fomentar a formação de grupos de aprendizagem tutorial no âmbito da Estratégia Saúde da Família, caracterizando-se como instrumento tanto para a qualificação em serviço dos profissionais da saúde quanto para a iniciação ao trabalho e vivências dirigidos aos estudantes das graduações em saúde, de acordo com as necessidades do SUS. 


\section{Referências}

ALMEIDA, Eugênia Zilioli de. As concepções do agente comunitário de saúde sobre promoção da saúde. 2008. Tese (Mestrado em Saúde Coletiva) - Departamento de Saúde Coletiva, Universidade de São Paulo, São Paulo, 2008.

ALVES, Vânia Sampaio. Um modelo de educação em saúde para o programa saúde da família: pela integridade da atenção e reorientação do modelo assistencial. Interface - Comunicação, Saúde, Educação, Botucatu, v. 9, n. 16, p. 39-52, 2004.

ARAÚJO, Marize B. de Souza; ROCHA, Paulo de Medeiros. Trabalho em equipe: um desafio para a consolidação da estratégia de saúde da família. Ciência \& Saúde Coletiva, Rio de Janeiro, v. 12, n. 2, p. 455464, 2007.

BRASIL. Ministério da Saúde. Secretaria de Políticas de Saúde. Projeto Promoção da Saúde. As Cartas da Promoção da Saúde. Brasília, DF: Ministério da Saúde, 2002.

Ministério da Saúde. Secretaria de Vigilância em Saúde. Secretaria de Atenção à Saúde. Politica Nacional de Promoção da Saúde. Brasília, DF: Ministério da Saúde, 2006.

BUSS, Paulo Marchiori. Promoção da saúde e qualidade de vida. Ciência \& Saúde Coletiva, Rio de Janeiro, v. 5, n. 1, p. 163-177, 2000.

CANTON, Giselle Alice Martins. O lazer como uma das possiveis estratégias de promoção da saúde nas classes subalternas: um estudo de caso na zona leste de São Paulo. 2008. Tese (Doutorado em Serviço Social) Pontifícia Universidade Católica de São Paulo, São Paulo, 2008.

CARVALHO, Sérgio Resende; GASTALDO, Denise. Promoção à saúde e empoderamento: uma reflexão a partir das perspectivas crítico-social pós-estruturalista. Ciência \& Saúde Coletiva, Rio de Janeiro, v. 13, supl. 2, p. 2.029-2.040, 2008. Disponível em: <www. scielo.br/pdf/csc/v13s2/v13s2a07.pdf $>$. Acesso em: 6 mar. 12.

CERVERA, Diana Patricia Patino; PARREIRA, Bibiane Dias Miranda; GOULART, Bethania Ferreira. Educação em saúde: percepção dos enfermeiros da atenção básica em Uberaba (MG). Ciência \& Saúde Coletiva, Rio de Janeiro, v. 16, supl. 1, p. 1.5471.554, 2011. Disponível em: <www.scielo. br/pdf/csc/v16sl/a90v16sl.pdf>. Acesso em: 18 jan. 2010.

FREIRE, Paulo. Pedagogia do oprimido. 47. ed. Rio de Janeiro: Paz e Terra, 2005.

HEIDMANN, Ivonete T. S. Buss et al. Promoção à saúde: trajetória histórica de suas concepções. Texto \& Contexto Enfermagem, Florianópolis, v. 15, n. 2, p. 352-358, abr.jun. 2006. Disponível em: <www.scielo.br/ pdf/tce/v15n2/a20v15n2.pdf $>$. Acesso em: 16 abr. 2012.

HORTA, Natália de Cássia et al. A prática das equipes de saúde da família: desafios para a promoção de saúde. Revista Brasileira de Enfermagem, Brasília, v. 62, n. 4, p. 524-529, jul.-ago. 2009a.

A prática de grupos como ação de promoção da saúde na Estratégia Saúde da Família. Revista de Atenção Primária à Saúde, Juiz de Fora, v. 12, n. 3, p. 293-301, jul.-set. 2009b.

LALONDE, M. A New Perspective on the Health of Canadians: a working document. Ottawa: Government of Canada, Ottawa, 1974. Disponível em: <www.nescon.medicina. ufmg.br/biblioteca/imagem/2130.pdf $>$. Acesso em: 20 jan. 2010.

LOPES, Sara Regina Souto et al. Potencialidades da educação permanente para a transformação das práticas de saúde. Comunicação em Ciências da Saúde, Brasília, v. 18, n. 2, p. 147-155, 2007. 
MELO, Gilberto; SANTOS, Regina Maria dos; TREZZA, Maria Cristina S. Figueiredo. Entendimento e prática de ações educativas de profissionais do Programa Saúde da Família de São Sebastião-AL: detectando dificuldades. Revista Brasileira de Enfermagem, Brasília, v. 58, n. 3, p. 290-295, maiojun. 2005.

MERHY, Emerson Elias. O desafio que a educação permanente tem em si: a pedagogia da implicação. Interface - Comunicação, Saúde, Educação, Botucatu, v. 9, n. 16, p. 172-174, set. 2004-fev. 2005.

MINAYO, Maria Cecília de Souza. O desafio do conhecimento: pesquisa qualitativa em saúde. 11. ed. São Paulo: Hucitec, 2008.

RICHARDSON, Roberto Jarry. Pesquisa social: métodos e técnicas. 3. ed. São Paulo: Atlas, 1999.

SANTOS, Marco Antônio Merechia; CUTOLO, Luiz Roberto Agea. A interdisciplinaridade e o trabalho em equipe no Programa de Saúde da Família. Arquivos Catarinenses de Medicina, Florianópolis, v. 33, n. 3, p. 31-40, 2004.
SÍCOLI, Juliana Lordello; NASCIMENTO, Paulo Roberto do. Promoção de saúde: concepções, princípios e operacionalização. Interface - Comunicação, Saúde, Educação, Botucatu, v. 7, n. 12, p. 91-112, 2003.

TEIXEIRA, Mirna Barros. Empoderamento de idosos em grupos de Promoção da Saúde. 2002. Tese (Mestrado em Saúde Pública) Departamento de Administração e Planejamento em Saúde, Escola Nacional de Saúde Pública, Fundação Oswaldo Cruz, Rio de Janeiro, 2002.

WESTPHAL, Márcia Faria. Promoção da saúde e prevenção de doenças. In: CAMPOS, Gastão Wagner de Souza et al. Tratado de saúde coletiva. 2. ed. São Paulo: Hucitec; Rio de Janeiro: Ed. Fiocruz, 2008. p. 635-667.

Recebido em 18/05/2011

Aprovado em 18/01/2012 